\title{
PANORAMA DA INCLUSÃO DAS PESSOAS COM DEFICIÊNCIA NO MERCADO DE TRABALHO NO BRASIL
}

\author{
OVERVIEW OF THE INCLUSION OF PEOPLE WITH DISABILITIES IN THE LABOR MARKET IN BRAZIL \\ PANORAMA DE LA INCLUSIÓN DE DISCAPACITADOS EN EL MERCADO LABORAL EN BRASIL
}

Vinicius Gaspar Garcia ${ }^{1}$

Resumo $\mathrm{O}$ artigo apresenta um mapeamento da inserção formal de pessoas com deficiência no mercado de trabalho brasileiro. Foram utilizados dados fornecidos pelo Instituto Brasileiro de Geografia e Estatística, no Censo Demográfico de 2010, no que tange às variáveis funcionalidade e deficiência. Adicionalmente, são utilizadas informações contidas na Relação Anual de Informações Sociais do Ministério do Trabalho e Emprego, que, a partir de 2007, passou a divulgar o número e o perfil dos vínculos empregatícios exercidos por pessoas com deficiência. Tal mapeamento é precedido por uma seção sobre linhas gerais do contexto histórico de inclusão social das pessoas com deficiência, além de uma síntese a respeito de legislações no campo da 'ação afirmativa'. A avaliação dos dados revela uma participação muito baixa das pessoas com deficiência no mercado de trabalho formal no Brasil, concentrada em atividades precárias, descontínuas e informais (ou inativo, sem exercer ocupações). Palavras-chave pessoas com deficiência; mercado de trabalho no Brasil; inclusão social.
Abstract The article presents a mapping of the formal insertion of people with disabilities in the Brazilian labor market. Data provided in the 2010 Census by the Brazilian Institute of Geography and Statistics with respect to the functionality and disability variables were used. Additionally, also used was information contained in the Ministry of Labor's Annual Social Information Report, which, from 2007 went on to publish the number and profile of jobs held by people with disabilities. Such mapping is preceded by a section on general lines of the historical context of the social inclusion of people with disabilities, as well as by an overview of the laws in the field of 'affirmative action'. A review of the data shows a very low level of participation of people with disabilities in the Brazilian formal labor market, one that concentrates mostly on poor, discontinuous and informal activities (or inactive, without holding occupations).

Keywords People with disabilities; the labor market in Brazil; social inclusion. 


\section{Introdução}

Este artigo busca traçar um panorama recente do acesso ao mercado formal de trabalho das pessoas com deficiência no Brasil. Para tanto, o primeiro passo é estimar a população com deficiência em idade produtiva - que potencialmente poderia estar ocupada no mercado de trabalho formal. Para essa tarefa, utilizam-se os dados do Censo Demográfico de 2010, realizado pelo Instituto Brasileiro de Geografia e Estatística (IBGE), que apurou a incidência de limitações funcionais e diferentes níveis de deficiência na população brasileira.

Naquilo que se refere ao acesso ao mercado de trabalho formal, regularizado e com registro em carteira profissional, estão disponíveis os dados da Relação Anual de Informações Sociais (Rais), do Ministério do Trabalho e Emprego (MTE), que, a partir de 2007, passou a divulgar o número e o perfil dos vínculos empregatícios exercidos por pessoas com deficiência. ${ }^{2}$

O cruzamento das informações contidas no Censo 2010 e na Rais 2010 permite uma avaliação contemporânea do cenário de inserção das pessoas com deficiência no mercado de trabalho formal. Especificamente, serão avaliados os seguintes aspectos: o percentual deste segmento populacional que consegue se inserir no mercado formal em comparação com o contingente potencial que ali poderia estar; o grau de formalização das pessoas com deficiência em face daquelas sem deficiência ou limitação funcional declarada; dentre aqueles que conseguem ingressar no mercado formal, os rendimentos médios obtidos; se existe maior participação de pessoas com determinados tipos de deficiência no mercado formal, em detrimento de outros grupos.

A apresentação desse panorama atual é precedida pela descrição das principais legislações que garantem acesso ao mercado de trabalho às pessoas com deficiência por meio das cotas no setor privado - lei n. 8.213 de 1991 (Brasil, 1991) - e vagas reservadas nos concursos públicos - lei n. 8.122 de 1990 (Brasil, 1990). Tais instrumentos de 'ação afirmativa' visam corrigir desvantagens históricas acumuladas ao longo do tempo pelas pessoas com deficiência, tidas anteriormente como 'incapazes' e 'inválidas', por vezes vítimas de preconceito e discriminação social (Figueira, 2008).

A realização de uma atividade de trabalho - respaldada por uma ocupação formal no mercado - especialmente para aqueles que estão em idade produtiva gera benefícios não só de natureza material, mas também em termos de realização e satisfação pessoal. No Brasil, em razão dos direitos trabalhistas e previdenciários que o trabalho com carteira assinada representa, a ocupação formal significa o acesso para a cidadania (Fagnani, 2005). Tal realidade, naturalmente, não é diferente para milhões de pessoas com deficiência no país, mesmo que eventualmente apoiadas por aposentadorias ou benefícios de assistência social (que são necessários, mas podem perpetuar 
situações de dependência). Daí a importância do mapeamento recente da inserção formal no trabalho das pessoas com deficiência.

Ao lado da reabilitação na esfera da saúde e da necessária inclusão escolar, o acesso ao trabalho se constitui em etapa decisiva para conquista plena da cidadania por parte desse segmento populacional. No final do artigo, são feitas considerações no intuito de sugerir ações e políticas que possam incrementar esse acesso no país, discutindo-se aspectos para além do cumprimento da legislação de 'ação afirmativa' e que se referem, em essência, às ideias de acessibilidade e equiparação de oportunidades como conceitos-síntese para plena inclusão social das pessoas com deficiência (Garcia, 2010).

\section{Contexto histórico e legislação nacional}

Em razão de um contexto histórico de exclusão do trabalho e do 'mundo social' - uma vez que as pessoas com deficiência eram vistas como 'inválidas', por vezes até escondidas por suas famílias -, forjou-se nas últimas décadas um aparato jurídico que visa garantir condições diferenciadas de acesso para este segmento no mercado formal. Tais legislações, em grande medida, refletem uma trajetória histórica na qual pessoas com deficiência procuraram formas de sobreviver, de superar uma condição de 'invisibilidade' e 'tutela' que lhes era imposta pela sociedade, além de uma carga negativa de preconceitos e discriminação.

Em termos da história mundial, Silva (1987) descreve o que ele chama de 'epopeia ignorada' das pessoas com deficiência. Em síntese, este autor mostra que, ao longo dos séculos, tais pessoas sobreviveram a partir de condições iniciais extremamente adversas, em que eram comuns, nas diferentes sociedades e culturas, a eliminação sumária de crianças com deficiência ou de pessoas que, ao longo da vida, adquirissem algum tipo de limitação física, sensorial ou cognitiva.

Da execução sumária ou marginalização social, passam-se séculos de história até que, gradativamente, desenvolvem-se práticas e tratamentos humanitários para o atendimento de pessoas com deficiência. Numa trajetória irregular e heterogênea entre os países (e entre as próprias pessoas com deficiência), é possível visualizar uma tendência geral de humanização das atitudes e dos comportamentos relacionados a esse grupo populacional. É verdade que, até nos dias de hoje, existem exemplos de discriminação e maus-tratos, mas o amadurecimento das civilizações e o avanço dos temas ligados à saúde, à cidadania e aos direitos humanos provocou, sem dúvida, um novo olhar em relação às pessoas com deficiência.

Figueira (2008) realiza trajetória semelhante àquela de Silva (1987), mas concentra-se na história do Brasil. Este autor propõe que seu livro marque 
uma introdução à história das pessoas com deficiência no país, definindo também sua tese principal, com a qual concordamos integralmente: "as questões que envolvem as pessoas com deficiência no Brasil - por exemplo, mecanismos de exclusão, políticas de assistencialismo, caridade, inferioridade, oportunismo, dentre outras - foram "construídas culturalmente" (Figueira, 2008, p. 17, destaque nosso). Assim, é importante termos em mente que questões culturais demoram a ser modificadas, mas esse é o movimento que tem sido empreendido pelas pessoas com deficiência e suas organizações representativas nas últimas décadas.

Nesse movimento, existe um marco histórico a partir do qual, em grande medida, as pessoas com deficiência deixaram de ser 'ignoradas' ou vistas apenas como objeto de caridade. Trata-se do ano de 1981, declarado pela Organização das Nações Unidas (ONU) como Ano Internacional da Pessoa Deficiente. De acordo com Figueira (2008),

Se até aqui a pessoa com deficiência 'caminhou em silêncio', excluída ou segregada em entidades, a partir de 1981 - Ano Internacional da Pessoa Deficiente -, tomando consciência de si, passou a se 'organizar politicamente'. E, como consequência, a ser notada na sociedade, atingindo significativas conquistas em pouco mais de 25 anos de militância (Figueira, 2008, p. 115, destaques nossos).

Assim, é a partir desse marco que se constroem legislações de caráter social e voltadas para equiparação de oportunidades para aqueles com limitações físicas, sensoriais ou cognitivas. Ao lado desse contexto histórico de superação da 'invisibilidade', a existência dessas legislações é outro fator a influenciar o acesso das pessoas com deficiência ao mercado de trabalho nos dias atuais.

Numa perspectiva mais ampla, interessante observar que, na década de 1980, coincide com o 'despertar' do movimento social e político das pessoas com deficiência o momento de redemocratização do país, após duas décadas de regime militar. Nesse contexto, a convocação de uma Assembleia Constituinte foi o principal instrumento para restabelecer o Estado Democrático de Direito. A Assembleia Constituinte era vista como a 'solução-síntese' ou o 'berço da democracia' pelos setores que combateram o regime militar entre 1964 e 1985 (Fagnani, 2005). Nesse processo, foi fundamental o fortalecimento dos movimentos sociais que se reorganizavam depois do período repressivo e autoritário das décadas de 1960 e 1970.

Conforme salientado, essa nova etapa da democracia brasileira se desenvolve de forma concomitante ao fortalecimento do movimento organizado das pessoas com deficiência, a partir de 1981, o que contribuiu para a inclusão de vários artigos na Constituição de 1988 que mencionam diretamente esse contingente populacional, como apresentado no Quadro 1. 
Artigo 7 - proíbe "qualquer discriminação no tocante a salário e critérios de admissão do trabalhador portador de deficiência".

Artigo 23 - estabelece a "competência comum" da União, dos estados, do Distrito Federal e dos municípios para "cuidar da saúde, da assistência social, da proteção e garantia das pessoas portadoras de deficiência". Artigo 37 - prevê que legislação complementar "reservará percentual dos cargos e empregos públicos para as pessoas portadoras de deficiência e definirá os critérios de sua admissão".

Artigo 203 - no inciso V postula a "garantia de um salário mínimo de benefício mensal à pessoa portadora de deficiência e ao idoso que comprovem não possuir meios de prover à própria manutenção ou de tê-la provida por sua família, conforme dispuser a lei".

Artigo 208 - estabelece que "o dever do Estado com a Educação será efetivado mediante a garantia do, entre outros aspectos, atendimento educacional especializado aos portadores de deficiência, preferencialmente na rede regular de ensino".

Artigo 227 - garante o acesso das pessoas portadoras de deficiência aos logradouros públicos: "a lei disporá sobre normas de construção dos logradouros e dos edifícios de uso público e da fabricação de veículos de transporte coletivo, a fim de garantir acesso adequado às pessoas portadoras de deficiência".

Fonte: Fagnani, 2005, p. 241.

O texto constitucional definiu diretrizes gerais e garantiu direitos que, na maioria dos casos, dependeriam de legislação posterior para sua regulamentação. Os artigos da Constituição pinçados aqui ilustram que, assim como para todas as pessoas, os direitos dos 'portadores de deficiência' se referem às mais variadas áreas e temáticas sociais, desde a não discriminação no trabalho até a acessibilidade (numa terminologia mais recente), passando pelas áreas clássicas como saúde e educação. Nesse sentido, ao estabelecer os princípios gerais, a Constituição lançou luz para legislações futuras.

No campo das pessoas com deficiência, procurando normatizar tais princípios, um ano após a Constituição, em 1989, editou-se a lei n. 7.853 de 1989 (Brasil, 1989), que definia uma "política nacional de integração para pessoa portadora de deficiência". Interessante registrar como os termos então utilizados refletem o paradigma que prevalecia naquela época para lidar com essa temática. Ao propor a 'integração' do 'portador de deficiência', estava implícita a ideia de que deveria haver a reabilitação individual para que, por méritos próprios e o mais próximo possível de um padrão de 'normalidade', essa pessoa pudesse ser integrada ou reintegrada nos sistemas gerais de educação, saúde e trabalho (Sassaki, 1997).

Atualmente, o chamado paradigma da 'inclusão' - que substitui a ideia de 'integração' - atribui responsabilidades maiores à sociedade e ao Estado no sentido de que existam condições de acessibilidade e inclusão para todas as pessoas, independentemente das limitações físicas, sensoriais ou cognitivas. 
De qualquer forma, a 'política de integração' definida na lei n. 7.853 de 1989 representou um avanço para a época, superando-se um período de segregação, reclusão e marginalização social das pessoas com deficiência. No que tange ao acesso ao trabalho, com base no artigo 37 da Constituição Federal (Quadro 1), esta legislação reafirmou a necessidade da “adoção de legislação específica que discipline a reserva de mercado de trabalho em favor das pessoas portadoras de deficiência, nas entidades da Administração Pública e do setor privado" (alínea d, seção III, artigo 2 ${ }^{\circ}$, lei n. 7.853 de 1989).

A partir daí, no início da década de 1990, duas leis de caráter geral, a lei n. 8.122 de 1990, sobre o "regime jurídico dos servidores públicos da União", e a lei n. 8.213 de 1991, sobre "benefícios da Previdência Social", estabeleceram os termos para a reserva de vagas em concursos públicos e as cotas nas empresas privadas, respectivamente.

No capítulo I (do provimento), na seção I (disposições gerais), da lei n. 8.122 de 1990, encontra-se o artigo $5^{\circ}$, parágrafo segundo, que postula:

(...) às pessoas portadoras de deficiência é assegurado o direito de se inscrever em concurso público para o provimento de cargos cujas atribuições sejam compatíveis com a deficiência de que são portadoras; para tais pessoas serão reservadas até $20 \%$ (vinte por cento) das vagas oferecidas no concurso (Brasil, 1990).

Pretendeu-se, assim, dar garantias legais para aplicação de uma 'ação afirmativa' relacionada às pessoas com deficiência (da mesma forma que se faria com as cotas no setor privado na lei n. 8.213 de 1991). Vale sempre observar, assim como faz Gugel (2005, p. 15), que ações afirmativas significam a "adoção de medidas legais e de políticas públicas que objetivam eliminar as diversas formas e tipos de discriminação que limitam oportunidades de determinados grupos sociais". Portanto, só fazem jus a essa política grupos historicamente discriminados e que, na realidade cotidiana, tenham limitadas suas 'oportunidades' em termos da formação escolar e do acesso ao trabalho, dentre outros aspectos.

Tal discussão é importante porque, na atualidade, alguns grupos populacionais defendem para si o 'direito de serem reconhecidos como pessoas com deficiência', justamente para usufruírem de vagas reservadas, cotas, isenções fiscais e outros benefícios. Trata-se de uma discussão polêmica que não será aqui aprofundada, mas é preciso adotar critérios técnicos para que direitos legitimamente conquistados não sejam banalizados e se transformem em privilégios.

A lei n. 8.213 de 1991, por sua vez, ao tratar dos benefícios da Previdência Social, incluiu na subseção sobre "habilitação e reabilitação profissional" a seguinte determinação (Quadro 2): 
Artigo 93 da lei n. 8.213 de 1991 - 'Lei de Cotas'

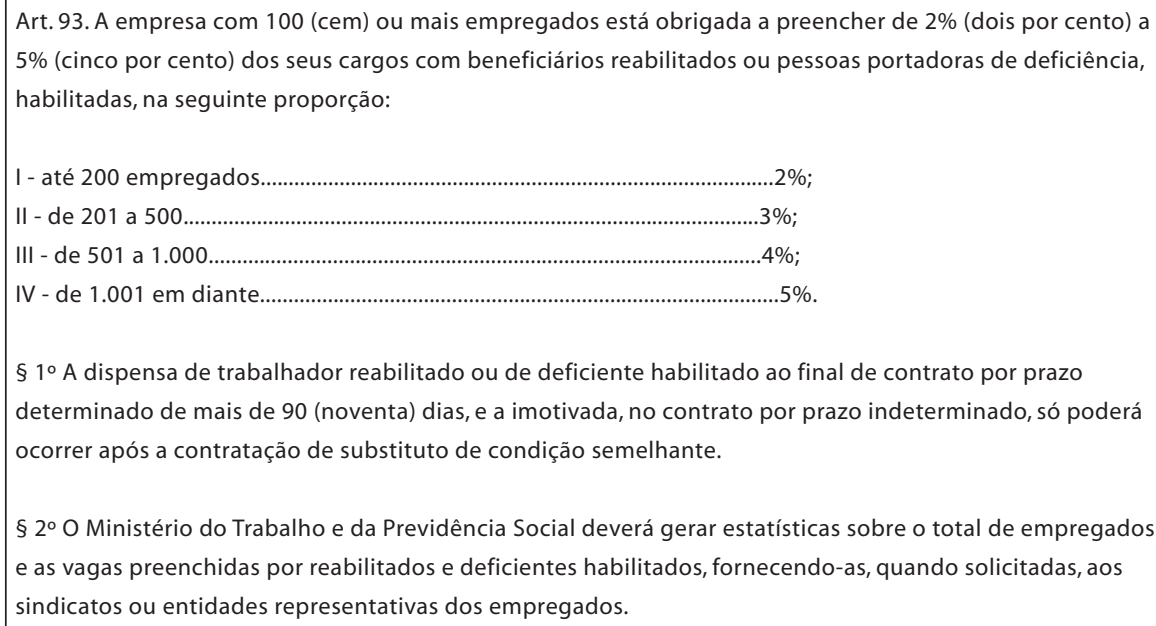

Fonte: Lei n. 8.213 de 1991 (Brasil, 1991).

Esse artigo é conhecido usualmente como a 'Lei de Cotas', pois a partir dele legislações posteriores normatizaram a fiscalização das empresas, as multas a serem aplicadas, os tipos de deficiência considerados para fins de cumprimento das cotas, dentre outros aspectos essenciais para aplicação e execução das vagas reservadas no mercado de trabalho privado.

O problema é que esse processo foi demasiadamente demorado, pois somente em 1999, com a edição do decreto federal n. 3.298 de 1999 (Brasil, 1999), é que tanto as vagas nos concursos públicos como as cotas no setor privado foram definitivamente regulamentadas. Como afirma Moro (2007, p. 84): “a regulamentação demorou dez anos para vir a lume, numa demonstração de que os direitos dos deficientes foram, ao longo de tantos anos, relegados a um segundo plano".

Mesmo com esse problema, o fato é que, a partir dos anos $2000-$ portanto, há mais de doze anos - existe um arcabouço legal que visa facilitar a inclusão de pessoas com deficiência no mercado de trabalho, reconhecendo o passivo histórico de exclusão que vitimou tal segmento e criou barreiras efetivas para sua natural inserção no mundo do trabalho.

Esse direito inalienável ao trabalho - assim como outros nas esferas de saúde, educação, proteção social, vida independente e cidadania - está reafirmado na Convenção Internacional sobre os Direitos das Pessoas com 
Deficiência (Convenção Internacional..., 2006). Tal documento aprovado pelas Nações Unidas em 2006 por um colegiado de quase duzentos países, foi internalizado e ratificado pelo Brasil, com status de emenda constitucional, por meio do decreto federal n. 6.949 de 2009 (Brasil, 2009). Constitui-se, assim, no novo 'farol' para aperfeiçoar e balizar legislações futuras sobre a temática da deficiência e inclusão no país.

O panorama histórico inicialmente apresentado e o breve painel sobre as legislações de 'ação afirmativa' buscaram dar subsídios e contextualizar a discussão que se fará na próxima seção. Dado o contexto histórico e a existência das leis de 'ação afirmativa' e de ampla 'legislação cidadã', qual o cenário atual de inserção das pessoas com deficiência no mercado de trabalho? Como se verá, mesmo com avanços e conquistas nos campos social e jurídico, ainda persistem problemas e desafios para a inclusão efetiva de um maior número de pessoas com deficiência no mercado de trabalho formal.

\section{População com deficiência e inclusão no mercado de trabalho}

Esta seção divide-se em três subitens. Em primeiro lugar, realiza-se uma exposição acerca dos procedimentos metodológicos utilizados para obtenção dos dados. Tal tratamento somente foi possível porque nos últimos dois Censos Demográficos realizados (2000 e 2010) houve a inclusão da variável 'incapacidade/deficiência' no questionário amostral. Essa iniciativa trouxe maiores possibilidades para que se conhecesse a realidade socioeconômica do contingente de pessoas com alguma deficiência ou incapacidade funcional no Brasil, mas exige cuidados na definição dos critérios e conceitos a serem considerados. No segundo subitem, são apresentados os resultados obtidos no dimensionamento da população com deficiência em idade produtiva e no seu acesso ao mercado de trabalho formal. No final, realiza-se uma breve revisão bibliográfica e discussão sobre temas decorrentes da avaliação dos dados.

\section{Notas metodológicas}

A definição sobre quem são pessoas com deficiência não é tarefa simples nem consensual. Existe uma gama variada de limitações físicas, sensoriais e cognitivas que correspondem a diferentes níveis de dificuldade funcional. Ademais, atualmente trabalha-se com o chamado 'paradigma social' da deficiência, segundo o qual, para além dos impedimentos de ordem física, o que determina a condição de deficiência é o entorno social, o grau de acessibilidade e autonomia disponíveis para aquele indivíduo com deficiência (Sassaki, 2007). ${ }^{3}$ 
Porém, quando se trata da avaliação de políticas públicas, da concessão de benefícios e exercício de direitos concedidos por lei, é preciso definir critérios técnicos e mais objetivos para que não se cometam injustiças. No caso da 'Lei de Cotas', por exemplo, são consideradas pessoas com deficiência aquelas que, mediante a apresentação de laudo médico, se enquadram nas definições de deficiência física, visual, auditiva, mental ou múltipla que constam do decreto federal n. 5.296 de 2004 (Brasil, 2004), da seguinte forma (Quadro 3):

Quadro 3

Artigo 4 do decreto n. 5.296/04 - Definição dos tipos de deficiência

a) Deficiência física: paraplegia, paraparesia, monoplegia, monoparesia, tetraplegia, tetraparesia, triplegia, triparesia, hemiplegia, hemiparesia, ostomia, amputação ou ausência de membro, paralisia cerebral,

nanismo, membros com deformidade congênita ou adquirida.

b) Deficiência auditiva: perda bilateral, parcial ou total, de quarenta e um decibéis (dB) ou mais, aferida por audiograma nas frequências de $500 \mathrm{~Hz}, 1.000 \mathrm{~Hz}, 2.000 \mathrm{~Hz}$ e $3.000 \mathrm{~Hz}$.

c) Deficiência visual: cegueira, na qual a acuidade visual é igual ou menor que 0,05 no melhor olho, com a melhor correção óptica; a baixa visão, que significa acuidade visual entre 0,3 e 0,05 no melhor olho, com a melhor correção óptica; os casos nos quais a somatória da medida do campo visual em ambos os olhos for igual ou menor que 60\%; e ocorrência simultânea de quaisquer das condições anteriores.

d) Deficiência mental: funcionamento intelectual significativamente inferior à média, com manifestação antes dos dezoito anos e limitações associadas a duas ou mais áreas de habilidades adaptativas, tais como: 1. comunicação; 2 . cuidado pessoal; 3 . habilidades sociais; 4 . utilização dos recursos da comunidade;

5. saúde e segurança; 6 . habilidades acadêmicas; 7 . lazer; e 8 . trabalho.

e) Deficiência múltipla: associação de duas ou mais deficiências.

Fonte: Decreto federal n. 5.296, de 2004 (Brasil, 2004).

Nos Censos Demográficos, não seria viável a utilização de critérios técnicos para indagar a população sobre o tema. Em outras palavras, não seria possível que o recenseador avaliasse a condição clínica da deficiência. Assim, quando da preparação para o Censo de 2000, em acordo com a então Coordenadoria para Integração da Pessoa Portadora de Deficiência (Corde), órgão de assessoria da Presidência da República nessa área, optou-se pela utilização da Classificação Internacional de Funcionalidades e Saúde (CIF) para avaliar a questão da deficiência mediante a autodeclaração do morador de cada domicílio, como ocorre com as demais variáveis. Dessa forma, as questões do Censo buscaram aferir o grau de dificuldade (total, grande, algum ou nenhum) para andar/subir escadas, ouvir e enxergar, além de uma 
pergunta específica sobre a deficiência mental. Essa estratégia foi repetida no Censo Demográfico de 2010, que apresentou os seguintes itens no questionário da amostra (Quadro 4):

Quadro 4

Questionário da amostra - Censo de 2010 - Deficiência e incapacidade

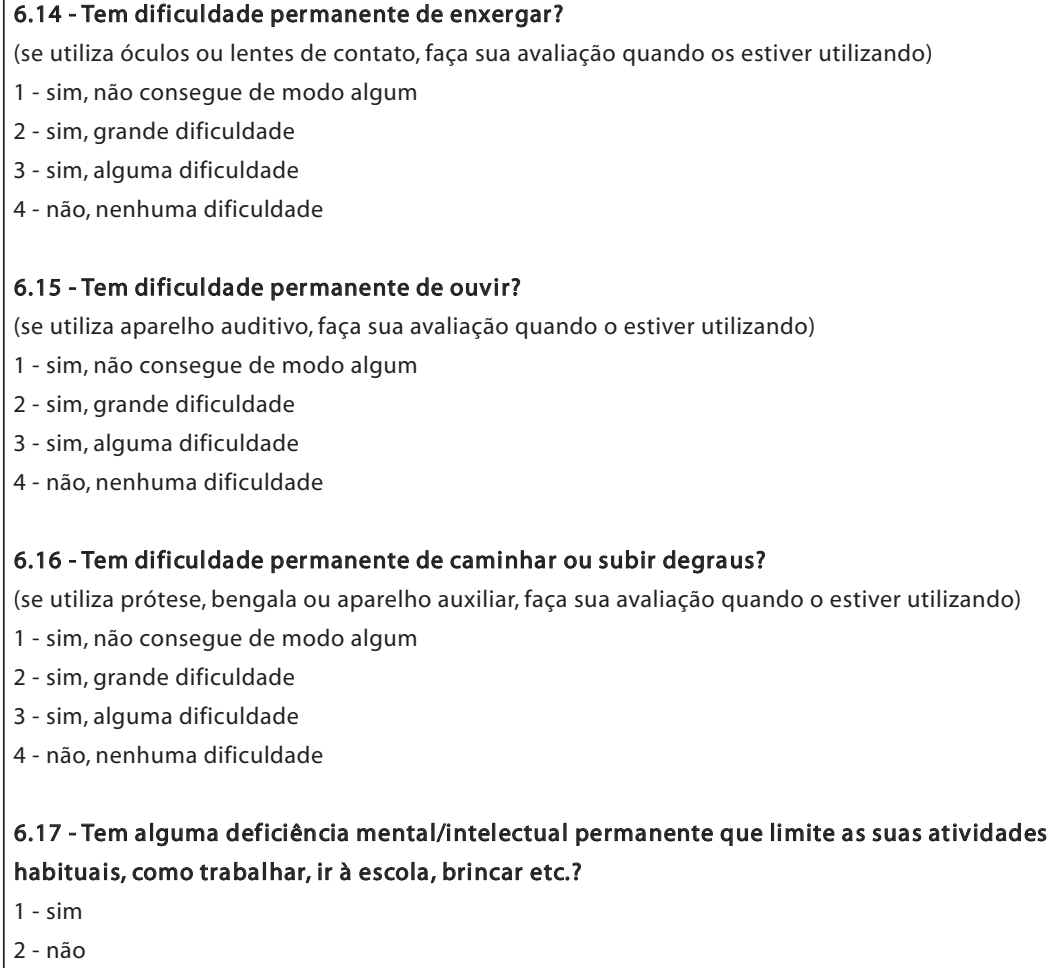

Fonte: Censo Demográfico de 2010. Questionário da amostra (IBGE, 2010). Disponível em: http://censo2010.ibge.gov.br/coleta/questionarios.

O desafio para estudiosos e pesquisadores do tema foi tentar compatibilizar as informações do Censo com as 'condições tradicionais' de deficiência física, sensorial ou mental. Na pesquisa "Retratos da deficiência no Brasil (2003)" (Centro de Pesquisas..., 2003), por exemplo, desenvolvida pelo Centro de Pesquisas Sociais da Fundação Getúlio Vargas (CPS/FGV), propõe-se uma análise com base em dois grupos distintos: o universo geral de pessoas portadoras de deficiência - que declararam qualquer tipo de deficiência ou incapacidade no Censo de 2000 (total, grande ou alguma); pessoas perceptoras de incapacidade (PPIs), restringindo apenas aquelas 
que declararam ter incapacidade 'total' para andar, ouvir e enxergar, além dos indivíduos com deficiência mental. Para que se tenha uma ideia, o primeiro grupo representava $14,5 \%$ da população pelo Censo de 2000, enquanto o último contingente - PPI - correspondia a apenas 2,5\% da população brasileira (Neri et al., 2003).

Além da tentativa de captar as 'deficiências convencionais', tal proposta metodológica de divisão num subgrupo para considerar apenas deficiências mais severas decorreu da seguinte constatação:

(...) há um inflacionamento das deficiências no Censo de 2000, pois ao incorporar no universo dos deficientes as pessoas com alguma ou grande dificuldade de caminhar, enxergar ou ouvir, o Censo acabou por classificar grande parte da população idosa como tal, uma vez que essas dificuldades funcionais tendem a acompanhar o processo natural de envelhecimento (Neri et al., 2003, p. 53).

A constatação sobre o superdimensionamento das deficiências é correta, porém essa proposta metodológica, em nosso entendimento, limita ao extremo a população com deficiência. Além daqueles que se declararam totalmente incapazes para caminhar, enxergar ou ouvir, nos parece apropriado incluir os indivíduos que disseram ter 'grande' dificuldade para realizar tais ações, deixando de fora apenas os que afirmaram ter 'alguma' dificuldade, já nos termos do questionário amostral do Censo de 2010 (Garcia, 2010). Procedendo dessa forma, três grupos populacionais podem ser observados: 'pessoas com deficiência', dado por aquelas que disseram ter 'total' ou 'grande' incapacidade para enxergar, ouvir ou andar/subir escadas, acrescidos daquelas que assinalaram 'sim' quanto à 'deficiência intelectual/mental'; 'pessoas com limitação funcional', que declararam ter apenas 'alguma' dificuldade para enxergar, ouvir ou andar/subir escadas; e o contingente de pessoas que não declarou qualquer tipo de deficiência ou limitação funcional.

Esses critérios foram usados como parâmetros para extração dos microdados do Censo Demográfico de 2010.4 Adicionalmente, as informações foram filtradas para considerar apenas aqueles em idade produtiva, numa faixa etária entre 20 e 59 anos, que potencialmente poderiam estar no mercado de trabalho. Excluem-se, assim, as crianças e os jovens (supostamente dedicados à formação escolar/acadêmica) e aqueles com 60 anos ou mais de idade (cujas limitações funcionais podem ser decorrentes do processo natural de envelhecimento).

Já em relação aos dados da Relação Anual de Informações Sociais (Rais), vale esclarecer que este é um levantamento anual realizado pelo Ministério do Trabalho e Emprego. Tanto as empresas privadas como autarquias e órgãos públicos são obrigados a declarar a Rais, sendo esta uma responsabilidade 
do empregador. No caso das pessoas com deficiência, além de outras variáveis como sexo, cor e idade, passou-se a exigir dos declarantes a inclusão dessa característica no perfil dos vínculos formais de cada estabelecimento. Isso só ocorreu a partir de 2007, sendo esse número utilizado para 'medir o tamanho' do mercado de trabalho 'formal' ocupado por pessoas com deficiência no Brasil. Diferentemente dos microdados do Censo, que necessitam de uma programação estatística para serem gerados, as informações da Rais e seus resultados definitivos estão disponíveis no site do Ministério do Trabalho e Emprego.

\section{Resultados: população com deficiência e o mercado de trabalho}

A Tabela 1 apresenta, de acordo com os parâmetros da seção anterior, a população em idade produtiva segundo os diferentes níveis de incapacidade funcional ou deficiência.

Tabela 1

População segundo tipo de deficiência - Brasil.

\begin{tabular}{|c|c|c|c|}
\hline \multirow{2}{*}{ Tipo } & \multirow{2}{*}{ Categorias } & \multicolumn{2}{|c|}{2010} \\
\hline & & $N(1000)$ & $\%$ \\
\hline \multirow[t]{2}{*}{ Deficiência mental/intelectual permanente } & Sim & 1.496 & 1,4 \\
\hline & Não & 1015.710 & 98,6 \\
\hline \multirow[t]{4}{*}{ Capacidade de enxergar (permanente) } & Incapaz & 252 & 0,2 \\
\hline & Grande dificuldade & 3.253 & 3,0 \\
\hline & Alguma dificuldade & 18.421 & 17,2 \\
\hline & Nenhuma & 85.260 & 79,5 \\
\hline \multirow[t]{4}{*}{ Capacidade de ouvir (permanente) } & Incapaz & 195 & 0,2 \\
\hline & Grande dificuldade & 670 & 0,6 \\
\hline & Alguma dificuldade & 3.501 & 3,3 \\
\hline & Nenhuma & 102.838 & 95,9 \\
\hline \multirow{4}{*}{$\begin{array}{l}\text { Capacidade de caminhar/subir escadas } \\
\text { (permanente) }\end{array}$} & Incapaz & 235 & 0,2 \\
\hline & Grande dificuldade & 1.432 & 1,3 \\
\hline & Alguma dificuldade & 4.158 & 3,9 \\
\hline & Nenhuma & 101.376 & 94,5 \\
\hline \multirow[t]{3}{*}{ Classificação } & Pessoa com deficiência & 6.495 & 6,1 \\
\hline & Pessoa com limitação funcional & 20.572 & 19,2 \\
\hline & $\begin{array}{l}\text { Pessoa sem deficiência ou limitação } \\
\text { funcional }\end{array}$ & 80.120 & 74,7 \\
\hline Total em 'idade produtiva' & & 107.188 & 100 \\
\hline
\end{tabular}

Fonte: Microdados do Censo Demográfico de 2010 (Instituto Brasileiro de Geografia e Estatística, 2010). Nota: Dados trabalhados pelo autor. 
De acordo com o Censo Demográfico de 2010, tínhamos no Brasil, naquele ano, pouco mais de 107 milhões de pessoas na faixa etária entre 20 e 59 anos completos. Em teoria, pode-se esperar que tal contingente esteja ocupado ou busque uma ocupação no mercado de trabalho. Neste é que se avaliou a participação de pessoas com deficiência ou limitação funcional.

Conforme a metodologia sugerida, consideraram-se 'pessoas com deficiência' aquelas totalmente incapazes ou com grande dificuldade para enxergar, ouvir ou caminhar/subir escadas, além das que responderam afirmativamente quanto à deficiência mental/intelectual. Com esses critérios, a população com deficiência no Brasil, em 2010, em idade produtiva, correspondia a um contingente de praticamente ' 6,5 milhões de pessoas' $(6,1 \%$ daqueles na faixa etária entre 20 e 59 anos; e 3,4\% se tomamos o conjunto da população brasileira de 190,7 milhões de pessoas). ${ }^{5}$

Em nosso entendimento, quando se procura fazer uma avaliação mais realista sobre a eficácia de instrumentos de 'ação afirmativa', por meio do mapeamento da inserção no mercado formal, é a este universo de 6,5 milhões de pessoas que devemos nos referir, pois ele cumpre os requisitos de contemplar: indivíduos que supostamente, pela idade, poderiam estar trabalhando formalmente; e pessoas com limitações funcionais significativas, para as quais as formas de acesso diferenciado ao trabalho foram pensadas.

Ainda de acordo com a Tabela 1, é possível identificar a existência de quase 1,5 milhão de pessoas com deficiência mental/intelectual; 3,5 milhões com 'deficiência visual' (sendo 250 mil totalmente incapazes de enxergar); 865 mil pessoas com 'deficiência auditiva' (670 mil com grande dificuldade e 195 mil incapazes de ouvir); e 1,6 milhão com 'deficiência física/motora', na sua maioria com 'grande dificuldade' para andar/subir escadas (1,4 milhão). ${ }^{6}$ Tais frequências são importantes para se avaliar, mais à frente, a participação no mercado de trabalho formal pelo tipo de deficiência declarada.

Definidos tais parâmetros, é preciso compará-los com os dados mais recentes sobre a inclusão formal das pessoas com deficiência no mercado de trabalho. Desde 2007, a Rais fornecida pelo MTE tem divulgado o total de vínculos empregatícios formais exercidos por pessoas com deficiência. Na Tabela 2, observa-se a variação desse número entre 2007 e 2010, bem como a média de postos de trabalho, nesses quatro anos, ocupados por pessoas com deficiência. ${ }^{7}$ 
Tabela 2

Vínculos exercidos por pessoas com deficiência em 31/12, segundo o ano.

\begin{tabular}{cc}
\hline Ano & Vínculos \\
\hline 2007 & 348.818 \\
2008 & 323.210 \\
2009 & 288.593 \\
2010 & 306.013 \\
& \\
Média dos 4 anos & 316.659 \\
\hline
\end{tabular}

Fonte: Brasil (s/d)

Nota: Dados trabalhados pelo autor.

De acordo com as declarações das empresas ao MTE, em média, '316 mil pessoas com deficiência' estiveram inseridas formalmente no mercado de trabalho brasileiro no período considerado. Ao comparar esse número com a população com deficiência em idade produtiva, aproximadamente 6,5 milhões de pessoas, percebe-se o quão baixa (irrisória) é a participação deste segmento no trabalho formal. Em termos percentuais, apenas ' $4,9 \%$ das pessoas com deficiência' estão no mercado formal de trabalho no Brasil. 8

Os dados da Tabela 3 nos fornecem informações adicionais sobre a situação ocupacional das pessoas com deficiência (PCD) no Brasil, em contraste com as pessoas sem deficiência ou limitação funcional (PSDLF).

Tabela 3

\begin{tabular}{lcc} 
População com deficiência, segundo tipo de atividade - Brasil. \\
\hline \multicolumn{2}{c}{2010} \\
Condição de atividade & PCD & \\
& & \\
& & \\
& 6.495 & 80.120 \\
População em idade produtiva (N=100) & 3.164 & 57.719 \\
População ocupada (N=100) & 289 & 4.264 \\
População desempregada (N=100) & 53,2 & 77,4 \\
Taxa de participação (\%) & 8,4 & 6,9 \\
Taxa de desemprego (\%) & & \\
&
\end{tabular}

Fonte: Microdados do Censo Demográfico de 2010 (Instituto Brasileiro de Geografia e Estatística, 2010). Nota: Dados trabalhados pelo autor.

PCD: pessoas com deficiência

PSDLF: pessoas sem deficiência ou limitação funcional 
No contingente de quase 6,5 milhões de pessoas com deficiência em 'idade produtiva', 3,1 milhões estão ocupadas. Como o número de vínculos formais, segundo a Rais de 2010, é de apenas 306 mil (Tabela 2), conclui-se que grande parte das pessoas com deficiência ocupadas está no mercado informal, exercendo atividades precárias, descontínuas, sem cobertura trabalhista e previdenciária.

Há um contingente de 289 mil pessoas com deficiência que está procurando emprego, na condição de desempregadas. Somando este número com o total de ocupados, e dividindo pelo total da população em idade produtiva, obtém-se a 'taxa de participação' para a população com deficiência, que é de $53,2 \%$, bem abaixo da taxa verificada no conjunto de trabalhadores sem deficiência (de 77,4\%). Essa informação confirma que, dentre aqueles com deficiência, mesmo em idade produtiva (entre 20 e 59 anos), há uma parcela considerável de 'inativos' (pouco mais de três milhões de pessoas). É possível imaginar que esse conjunto de indivíduos sobreviva do recebimento de pensões, benefícios assistenciais, previdenciários ou com base no suporte familiar.

Ainda sobre a taxa de desemprego, que é de $8,4 \%$ para as pessoas com deficiência, interessante observar que ela é 1,5 ponto percentual mais elevada do que a taxa observada para a população sem deficiência $(6,9 \%)$, o que sugere dificuldades adicionais para este segmento na procura pelo trabalho.

Para finalizar esse panorama recente acerca da inclusão de pessoas com deficiência no mercado de trabalho, os dados da Tabela 4 apresentam a composição dos vínculos formais pelo tipo de deficiência na Rais de 2010, além dos rendimentos médios correspondentes a cada grupo.

Tabela 4

Total de empregos e remuneração média - Brasil, 2010.

\begin{tabular}{lccc}
\hline PCD & N & $\%$ & R\$ \\
\hline Física & 166.690 & 54,5 & $2.025,96$ \\
Auditiva & 68.819 & 22,5 & $1.925,67$ \\
Visual & 17.710 & 5,8 & $1.768,54$ \\
Mental/intelectual & 15.606 & 5,1 & 772,20 \\
Múltipla & 3.845 & 1,3 & $1.376,38$ \\
Reabilitados & 33.343 & 10,9 & $2.107,27$ \\
& & & $1.922,90$ \\
Total PCD & 306.013 & 100,0 & $1.922,90$ \\
& & & $1.740,77$ \\
Com deficiência declarada & 306.013 & 0,7 & $1.742,00$ \\
Sem deficiência declarada & 43.762 .432 & 99,3 & \\
Total de empregos & 44.068 .355 & 100,0 & \\
& & & \\
\hline
\end{tabular}

Fonte: Brasil (s/d).

Nota: Dados trabalhados pelo autor.

PCD: pessoas com deficiência 
Dentre aquelas pessoas com deficiência que conseguem exercer um vínculo formal, há o predomínio daquelas com deficiência física, que respondem por $54,5 \%$ dos postos de trabalho em 2010. Na sequência, aparecem as pessoas com deficiência auditiva, com uma participação de $22,5 \%$, e os chamados 'reabilitados', com 10,9\% (indivíduos que sofreram acidente de trabalho e se reintegraram ao mercado, que também fazem jus à 'Lei de Cotas' - Quadro 2). Há uma clara sub-representação no mercado formal das pessoas com deficiência visual ou mental/intelectual, que representam apenas pouco mais de 5,0\% das vagas geradas. ${ }^{9}$

Outra forma de avaliar as diferenças pelo tipo de deficiência é comparar o número de empregos com o contingente total daqueles com deficiência física, auditiva, visual ou mental. Vimos na Tabela 1 que 1,6 milhão de pessoas disseram ter total ou grande incapacidade para andar/subir escadas. Dado o número de 166 mil vínculos exercidos por pessoas com deficiência física (Tabela 4), pode-se dizer que a taxa de participação no mercado formal é de 10,0\% para aqueles com deficiência física. Esse mesmo percentual é de $8,0 \%$ para as pessoas com deficiência auditiva, e de apenas 1,0\% para aqueles com deficiência mental ( 15 mil postos de trabalho numa população de quase 1,5 milhão de pessoas). No caso das pessoas com deficiência visual, a dificuldade para acesso ao mercado formal é ainda maior, pois numa população de quase 3,6 milhões de pessoas, apenas 17 mil - irrisório $0,5 \%$ - estavam no mercado formal segundo a Rais 2010 .

Em termos dos rendimentos médios, constatam-se algumas observações: rendimento médio maior, de $\mathrm{R} \$ 1.922,90$, nos postos de trabalho ocupados por pessoas com deficiência (superior em relação aos demais trabalhadores, sem deficiência declarada, de R $1.740,77)$; baixo rendimento médio das pessoas com deficiência mental/intelectual (significativamente inferior do que os demais grupos). O primeiro aspecto sugere que, de maneira geral, aquelas (poucas) pessoas com deficiência que conseguem ingressar no mercado formal o fazem em boas condições (pelo menos em termos do rendimento médio obtido). Já os rendimentos relativamente mais baixos daqueles com deficiência mental/intelectual muito provavelmente se devem ao fato de este grupo estar inserido em ocupações mais simples, com remunerações mais baixas.

\section{Discussão: pessoas com deficiência e o mercado de trabalho}

Dada a própria dinâmica capitalista - e os circuitos de desigualdade e fragilidade social que dela decorrem -, não é possível esperar que todas as pessoas com deficiência se insiram no mercado de trabalho formal (Rosa, 2009). Mais ainda, estamos longe de uma situação de acesso pelo que se chama de 'trabalho decente', em boas condições de ocupação e com um 
padrão significativo de remuneração, o que vale tanto para pessoas com deficiência como para os trabalhadores em geral (Sachs, 2004).

Ao mesmo tempo, porém, o processo de inclusão laboral de pessoas com deficiência no Brasil tem produzido experiências exitosas e enriquecedoras. Deve-se ter em mente que, ao contrário de outros países que adotaram ações afirmativas para inclusão desse segmento populacional em meados do século passado - como EUA e Inglaterra, que instituíram programas de cotas logo após a Segunda Guerra Mundial -, no Brasil a legislação nesse sentido é relativamente recente (Fávero, 2004; Assis e Pozzoli, 2005). Embora date do início da década de 1990, a chamada 'Lei de Cotas', como vimos, só foi regulamentada em 1999 (Brasil, 1999). Sua vigência e maior fiscalização impulsionaram um movimento que envolveu empresas privadas, agentes públicos, entidades de assistência, profissionais da área de saúde e reabilitação, além, é claro, das próprias pessoas com deficiência.

Nesse movimento, é interessante observar a percepção daqueles que são protagonistas: as pessoas com deficiência que buscaram trabalhar e se inserir socialmente. Toldrá (2009) colheu depoimentos de indivíduos com diferentes graus de limitação física e sensorial inseridos no mercado de trabalho. Em síntese, três ideias centrais decorrem da experiência prática dessas pessoas: se não houvesse a obrigatoriedade na legislação, as empresas não contratariam pessoas com deficiência; a lei de cotas permitiu, ao obrigar o movimento de contratação, a diminuição do preconceito e a visibilidade das diferentes potencialidades de trabalho da pessoa com deficiência; ainda permanece um déficit na formação escolar e capacitação desse contingente populacional, o que ajuda a explicar sua maior concentração em ocupações mais simples.

A questão educacional surge também em outros estudos que procuraram recuperar a trajetória de inclusão de pessoas com deficiência no trabalho. Para Shimono (2009), ao menos três dimensões constituem e dão corpo a esse processo de inclusão: o direito à educação, o direito ao trabalho e o direito de ser diferente.

Em relação ao primeiro aspecto, destaca-se o papel das famílias em busca de recursos educacionais de apoio, em particular em face da carência apresentada nas escolas públicas. Embora se reconheça a importância de que a pessoa com deficiência possa estar integrada nos sistemas regulares de ensino, as experiências descritas destacam o apoio complementar por meio de entidades especializadas, principalmente nos casos das deficiências visual, auditiva e intelectual.

Em boa medida, a trajetória escolar é definidora da segunda dimensão do processo de inclusão das pessoas com deficiência: o acesso ao trabalho. De acordo com a autora: "o caminho da inclusão teve início na escola que lhes garantiu a qualificação para um mercado cada vez mais exigente" (Shimono, 2009, p. 101). A 'Lei de Cotas', mais uma vez, é vista como ferramenta 
necessária, mas não suficiente porque a verdadeira inserção profissional envolve outros aspectos, como um ambiente de trabalho acessível e a ausência de comportamentos e condutas discriminatórias.

Finalmente, 'o direito de ser diferente' se relaciona com a ideia de valorização da diversidade e negação de modelos, padrões e estereótipos preconcebidos. Muitas vezes, ter uma deficiência é confrontar-se diariamente com o estigma da inferioridade ou da invalidez, de maneira que se autoassumir como pessoa capaz e produtiva é passo fundamental na trajetória de inclusão. E para isso contribui também o grau de conscientização da sociedade, seja na construção de políticas públicas inclusivas, seja no trato cotidiano com as chamadas 'minorias sociais'.

Os aspectos aqui relacionados dão subsídios importantes para a última seção deste artigo, em que se pretende pontuar questões para estimular o acesso de pessoas com deficiência ao mercado de trabalho.

\section{Considerações finais}

O contexto histórico marcado por uma trajetória de superação da invisibilidade e luta por cidadania caracteriza o caminhar das pessoas com deficiência. Rejeitadas sumariamente em diferentes sociedades e culturas, vistas durante muitos séculos como 'inválidas' ou 'incapazes', nas últimas décadas, particularmente depois de 1981 (declarado pela ONU como Ano Internacional da Pessoa Deficiente), esse grupo passou a se organizar politicamente, constituindo-se num novo 'ator social' nos debates contemporâneos sobre direitos humanos e políticas públicas.

A legislação nacional - considerada uma das mais avançadas no mundo sobre essa temática - confirma esse movimento, pois desde a Constituição Federal de 1988 até a Convenção Internacional sobre os Direitos das Pessoas com Deficiência, ratificada pelo país em 2008, foi definida uma gama variada de temas e direitos que são objeto de garantias legais. Particularmente no campo do acesso ao trabalho, destacamos a previsão de cotas a serem preenchidas nas empresas privadas e a reserva de vagas para pessoas com deficiência em concursos públicos.

Se avançamos na perspectiva histórico-cultural e, ao mesmo tempo, construímos um arcabouço jurídico adequado, por que os resultados apurados no final, no que tange ao acesso ao trabalho formal, não são bons? Por que persiste uma participação extremamente baixa das pessoas com deficiência nesse mercado?

De forma sintética e objetiva, na linha de observações já realizadas por outros autores, alguns aspectos podem ser relacionados para tentar responder a esses questionamentos: 
Acessibilidade precária. É fundamental que os municípios, as empresas, os espaços públicos e privados, os serviços de maneira geral, estejam $100 \%$ acessíveis às pessoas com deficiência. Infelizmente, mesmo com alguns avanços, estamos muito longe dessa realidade. As pessoas com deficiência física ou deficiência visual, por exemplo, encontram ainda grandes barreiras para sua mobilidade, o que lhes cria grandes dificuldades para estudar, procurar emprego ou trabalhar. Da mesma forma, recursos de comunicação inadequados, como a ausência de intérpretes de Linguagem Brasileira de Sinais (Libras), são impeditivos para a plena inserção social e laboral das pessoas com deficiência auditiva.

Permanência de estereótipos e preconceitos. Mesmo que grande parte da sociedade reconheça hoje o potencial produtivo das pessoas com deficiência, na realidade cotidiana persistem exemplos de condutas inapropriadas e até mesmo discriminatórias. O entendimento de que pessoas com deficiência mental/intelectual são totalmente incapazes ou problemáticas; a ideia de que os cegos necessitam o tempo todo de ajuda para suas atividades; a concepção de que a deficiência deva ser tratada somente com assistencialismo e piedade, ou que ela está sempre associada a doenças, são exemplos dessas condutas, as quais ainda têm um impacto real negativo na contratação de pessoas com deficiência.

Passivo escolar e na formação profissional. É preciso reconhecer que, ao longo de muitos anos, as pessoas com deficiência estiveram alijadas ou segregadas do sistema regular de ensino. Felizmente, esse processo tem sido alterado, já que há um consenso sobre os benefícios para as crianças com deficiência - e também para seus colegas e professores - da inclusão escolar na perspectiva da diversidade humana. Em outras palavras, a segregação em instituições especializadas (que devem ter um papel de suporte) prejudica o pleno desenvolvimento das crianças com deficiência. Tal mudança está em curso e ainda hoje, na média, a escolaridade das pessoas com deficiência é relativamente baixa, o que cria problemas para inserção profissional.

Inadequação e insuficiência da legislação. A chamada 'Lei de Cotas', ao estipular que as vagas a serem ocupadas por pessoas com deficiência devem ser cumpridas apenas nas empresas com cem ou mais empregados, define um limite matemático para sua execução. Se for cumprida na íntegra, cerca de 900 mil vagas seriam preenchidas por este segmento populacional (número insuficiente, dada a população de 6,5 milhões de pessoas com deficiência em idade produtiva). Existem propostas em discussão para que empresas a partir de cinquenta empregados também já sejam obrigadas a cumprir as cotas, o que aumentaria significativamente o número de vagas potenciais. Mas esse é um debate complicado porque também existem movimentos no sentido contrário, propondo flexibilizar a 'Lei de Cotas'. Outro problema decorre da legislação previdenciária, pois pessoas com deficiência 
que se aposentaram ainda jovens, e com limitações funcionais que não constituem impeditivo para o trabalho, só podem retornar ao mercado de trabalho formal se abrirem mão da aposentadoria por invalidez. Assim como foi feito para o benefício de prestação continuada - no âmbito da Assistência Social, voltado para idosos e pessoas com deficiência em situação de pobreza -, poder-se-ia estabelecer a cessação da aposentadoria em caso de trabalho formal remunerado e o retorno a ela se houver desemprego. Ou mesmo a manutenção da aposentadoria mesmo que a pessoa esteja trabalhando, pois as pessoas com deficiência têm uma série de despesas adicionais decorrentes de sua limitação funcional.

Questões culturais e próprias à temática da deficiência. Finalmente, é necessário romper com questões culturais como a superproteção familiar, que desestimula o trabalho de pessoas com deficiência, como também certo grau de acomodação e conformismo das próprias pessoas com deficiência, que por vezes perpetuam sua condição de dependência. Ademais, é importante deixar claro que nem todas as pessoas com deficiência vão estar aptas a trabalhar (assim como ocorre com a população em geral). Pode haver problemas de saúde ou outras situações de cunho pessoal ou familiar que dificultem ou mesmo desestimulem o acesso ao trabalho.

Em síntese, se for possível avançar nas áreas aqui mencionadas, especialmente com a participação direta das próprias pessoas com deficiência nas discussões que lhes dizem respeito, a tendência é que haja um aumento na participação desse contingente no mercado de trabalho formal. Essa conquista constitui-se numa etapa importante para conclusão do processo histórico de luta pela cidadania das pessoas com deficiência no Brasil.

Resumen El artículo presenta un mapeo de la inserción formal de discapacitados en el mercado laboral brasileño. Se utilizaron datos suministrados por el Instituto Brasileño de Geografía y Estadística, en el Censo Demográfico de 2010, en lo tocante a las variables funcionalidad y deficiencia. Además, se utilizó información contenida en el Compendio Anual de Informaciones Sociales del Ministerio de Trabajo y Empleo que, a partir de 2007, pasó a divulgar el número y el perfil de los vínculos laborales ejercicios por discapacitados. Dicho mapeo está precedido por una sección sobre líneas generales del contexto histórico de inclusión social de discapacitados, además de una síntesis a respecto de las legislaciones en el área de la "acción afirmativa". El análisis de los datos revela una participación muy baja de los discapacitados en el mercado laboral formal en Brasil, concentrada en actividades precarias, discontinuas e informales (o inactivo, sin ejercer ocupaciones).

Palabras clave Discapacitados; mercado laboral en Brasil; inclusión social. 


\section{Notas}

${ }^{1}$ Faculdades de Campinas (Facamp), Campinas, São Paulo, Brasil.

Doutor em Economia Social e do Trabalho pelo Instituto de Economia da Universidade Estadual de Campinas. <vggarcia30@gmail.com>

Correspondência: Faculdades de Campinas (Facamp), Estrada Municipal Unicamp-Telebrás, km 1, s/n, Cidade Universitária, CEP 13083-970, Barão Geraldo, Campinas, São Paulo, Brasil.

2 Em estudos posteriores, os próprios dados do Censo Demográfico de 2010 poderão ser detalhados no intuito de caracterizar a situação sócio-ocupacional das pessoas com deficiência.

3 A Convenção sobre os Direitos das Pessoas com Deficiência, citada no final da seção anterior, traz a seguinte definição, no artigo $1^{\circ}$ : “pessoas com deficiência são aquelas que têm impedimentos de longo prazo de natureza física, sensorial ou cognitiva, os quais, em interação com diversas barreiras, podem obstruir sua participação plena e efetiva na sociedade com as demais pessoas" (Convenção Internacional..., 2006).

4 Neste trabalho, agradecemos a valiosa contribuição do estatístico e professor do Instituto de Economia da Unicamp Alexandre Gori Maia, que gerou as tabelas utilizadas neste artigo com base no Censo de 2010.

5 Na Tabela 1, 'pessoas com limitação funcional' são aquelas que disseram ter apenas 'alguma dificuldade' para enxergar, ouvir ou caminhar/subir escadas.

6 Deve-se notar que o somatório de cada tipo excede os 6,5 milhões de 'pessoas com deficiência', o que ocorre porque um mesmo indivíduo pode ter declarado mais de um tipo de limitação.

7 Os números agregados correspondem, na base da Rais, ao total de empregos formais ou vínculos empregatícios num determinado momento, não exatamente ao número de trabalhadores ou pessoas empregadas. Isso ocorre porque um mesmo indivíduo pode ter mais de um vínculo formal. Tal situação não é predominante ou mesmo comum para o conjunto dos trabalhadores, e provavelmente menos ainda para aqueles que possuem uma deficiência (com mais dificuldades para ocupar dois empregos). Mas, de qualquer forma, é preciso ter claro que os dados se referem ao total de empregos ou postos de trabalho ocupados.

8 Conforme já mencionado, o detalhamento sobre os dados ocupacionais no Censo Demográfico de 2010 pode revelar novas características e até mesmo outra dimensão do mercado formal de pessoas com deficiência (já que esse dados se baseiam na autodeclaração, não numa informação fornecida pelo empregador, como no caso da Rais).

9 Outros trabalhos - como Clemente (2008) e Benevides (2011) - cujos conteúdos baseiam-se em experiências práticas de inclusão de pessoas com deficiência em municípios como Osasco e Campinas, respectivamente, no estado de São Paulo, comprovam também a prática de 'preferência' por algumas deficiências em detrimento de outras. 


\section{Referências}

ASSIS, Olney Q.; POZZOLI, Lafayete. Pessoa portadora de deficiência: direitos e garantias. 2. ed. São Paulo: Damásio de Jesus, 2005.

BENEVIDES, Guirlanda. Politicas de inclusão das pessoas com deficiência no mercado de trabalho: a experiência no município de Campinas/SP e Região - CESIT. Instituto de Economia. Campinas: Unicamp, 2011.

BRASIL. Lei n. 7.853 de 24 de outubro de 1989. Dispõe sobre o apoio às pessoas portadoras de deficiência, sua integração social, sobre a Coordenadoria Nacional para Integração da Pessoa Portadora de Deficiência - Corde, institui a tutela jurisdicional de interesses coletivos ou difusos dessas pessoas, disciplina a atuação do Ministério Público, define crimes, e dá outras providências. Disponível em: <www.planalto.gov.br/ccivil_03/ leis/17853.htm>. Acesso em: 27 set. 2012.

Lei n. 8.213 de 24 de julho de 1991. Dispõe sobre os Planos de Benefícios da Previdência Social e dá outras providências. Disponível em: <www.planalto.gov.br/ccivil_ 03/leis/18213cons.htm>. Acesso em: 20 set. 2012.

Lei n. 8.122 de dezembro de 1990. Dispõe sobre o regime jurídico dos servidores públicos da União, das autarquias e das fundações públicas federais. Disponível em: $<$ www010.dataprev.gov.br/sislex/paginas/ 42/1990/8112.htm>. Acesso em: 20 set. 2012.

Decreto federal n. 3.298, de 20 de dezembro de 1999. Regulamenta a lei n. 7.853, de 24 de outubro de 1989, dispõe sobre a Política Nacional para a Integração da Pessoa Portadora de Deficiência, consolida as normas de proteção, e dá outras providências. Disponível em: <www.planalto.gov. br/ccivil_03/decreto/d3298.htm>. Acesso em: 29 set. 2012.

Regulamenta as leis nos 10.048, de 8 de novembro de 2000 , que dá prioridade de atendimento às pessoas que especifica, e 10.098 , de 19 de dezembro de 2000, que es- tabelece normas gerais e critérios básicos para a promoção da acessibilidade das pessoas portadoras de deficiência ou com mobilidade reduzida, e dá outras providências. Disponível em: <www.planalto.gov.br/ccivil_ 03/_ato2004-2006/2004/decreto/d5296.htm >. Acesso em: 15 set. 2012.

Decreto n. 6.949, de 25 de agosto de 2009. Promulga a Convenção Internacional sobre os Direitos das Pessoas com Deficiência e seu Protocolo Facultativo, assinados em Nova York, em 30 de março de 2007. Disponível em: <http://presrepublica. jusbrasil.com.br/legislacao/818741/decreto6949-09>. Acesso em: 19 set. 2012.

Ministério do Trabalho e Emprego (MTE). Relação Anual de Informações Sociais (RAIS). Resultados Definitivos: 2007, 2008, 2009 e 2010. s/d. Disponível em: <http:// portal.mte.gov.br/rais/resultados-definitivos. htm >. Acesso em 23 set 2012.

CENTRO DE PESQUISAS SOCIAIS DA FUNDAÇÃO GETULIO VARGAS (CPS/FGV). 2003. Retratos da Deficiência no Brasil. Disponível em: $<$ http://cps.fgv.br/ppd>. Acesso em: 22 set 2012.

CLEMENTE, Carlos A. Trabalho decente: leis, mitos e práticas de inclusão. São Paulo: Editora do Autor, 2008.

CONVENÇÃO INTERNACIONAL SOBRE OS DIREITOS DAS PESSOAS COM DEFICIÊNCIA. Organização das Nações Unidas. CPDP/ONU. 2006. Disponível em: <www.un.org/disabilities/ convention/conventionfull.shtml $>$. Acesso em: 19 set. 2012.

FAGNANI, Eduardo. Politica social no Brasil (1964-2002): entre a cidadania e a caridade. 2005. 604f. Tese (Doutorado em Ciências Econômicas) - Instituto de Economia da Unicamp, Campinas, 2005.

FÁVERO, Eugênia A. Direitos das pessoas com deficiência: garantia de igualdade na diversidade. São Paulo: Editora WVA, 2004. 
FIGUEIRA, Emílio. Caminhando no silêncio: uma introdução à trajetória das pessoas com deficiência na história do Brasil. São Paulo: Giz Editora, 2008.

GARCIA, Vinicius G. Pessoas com deficiência e o mercado de trabalho: histórico e o contexto contemporâneo. 2010. 205 f. Tese (Doutorado em Ciências Econômicas) - Instituto de Economia da Unicamp, Campinas, 2010.

GUGEL, Maria A. Pessoas com deficiência e o direito ao trabalho. Brasília: Editora Letras Contemporâneas, 2005.

\section{INSTITUTO BRASILEIRO DE GEOGRAFIA} E ESTATÍSTICA (IBGE). Censo Demográfico de 2010. Resultados da Amostra. 2010. Disponível em: <www.ibge.gov.br/home/ estatistica/populacao/censo2010/default resultados_amostra.shtm $>$. Acesso em 19 set 2012 .

MORO, Luís C. A proteção trabalhista ao portador de deficiência física e as questões jurídicas decorrentes. Direitos das pessoas com deficiência. Revista dos Advogados, São Paulo, n. 95, dez. 2007.

NERI, Marcelo et al. Retratos da deficiência no Brasil. Rio de Janeiro: FGV/CPS, 2003.
ROSA, Enio R. O trabalho das pessoas com deficiência e as relações sociais de produção capitalista: uma análise crítica das políticas de cotas no Brasil. 2009. 249f. Dissertação (Mestrado em Educação) - Universidade Estadual do Oeste do Paraná, Cascavel, 2009.

SACHS, Ignacy. Inclusão social pelo trabalho decente: oportunidades, obstáculos, políticas públicas. Estudos Avançados, São Paulo, v. 18, n. 51, 2004.

SASSAKI, Romeu K. Inclusão: construindo uma sociedade para todos. Rio de Janeiro: WVA, 1997.

SHIMONO, Sumiko O. Educação e trabalho: caminhos da inclusão na perspectiva da pessoa com deficiência. 2009. 118f. Dissertação (Mestrado em Educação) - Universidade de São Paulo, São Paulo, 2009.

SILVA, Otto M. A epopeia ignorada: a pessoa deficiente na história do mundo de ontem e de hoje. São Paulo: Cedas, 1987.

TOLDRÁ, Rose C. Políticas afirmativas: opinião das pessoas com deficiência acerca da legislação de reserva de vagas no mercado trabalho. Revista Terapia Ocupacional da Universidade de São Paulo, São Paulo, v. 20, n. 2, p. 110-117, maio/ago. 2009.

Recebido em 22/11/2012

Aprovado em 04/03/2013 